\title{
The challenges of quantifying quality
}

Published at www.cmaj.ca on Feb. 22

$\mathrm{T}$ he value of a professional athlete is measured in numbers. The number of home runs hit. The number of goals scored. The number of three-pointers made. Numbers are also clear indicators of performance in other lines of work, such as sales. But in some professions, finding accurate statistical measures of quality is a challenge. Medicine is one of those professions.

"Medicine is still very much an art," says Dr. Jack Kitts, president and chief executive officer of the Ottawa Hospital in Ontario. "Everybody believes it's a science. It is more art than science."

But despite the many challenges of quantifying performance in medicine, hospitals must strive to find objective means to better determine where they are doing well and where they are doing poorly, says Kitts, a featured speaker at the fourth annual CEO Forum (Metrics For Healthcare Quality: The Leader's Role), held in Montréal, Quebec, on Feb. 17.

The forum - presented by the Canadian Health Services Research Foundation, the Canadian Medical Association and the Association of Canadian Academic Healthcare Organizations - brought together health care leaders from across Canada to share ideas on how to measure and improve quality and performance in medicine.

"Achieving higher quality of care within the Canadian healthcare system is necessary for reducing needless mortality, morbidity and excess costs. However, navigating a successful path is complex, with no single way of capturing quality and no simple route to higher performance," reads a statement on the forum's website (www.chsrf.ca/CEO _forum2010_e.php).

One of the biggest challenges of quantifying health care quality is determining what to measure. If you put 10

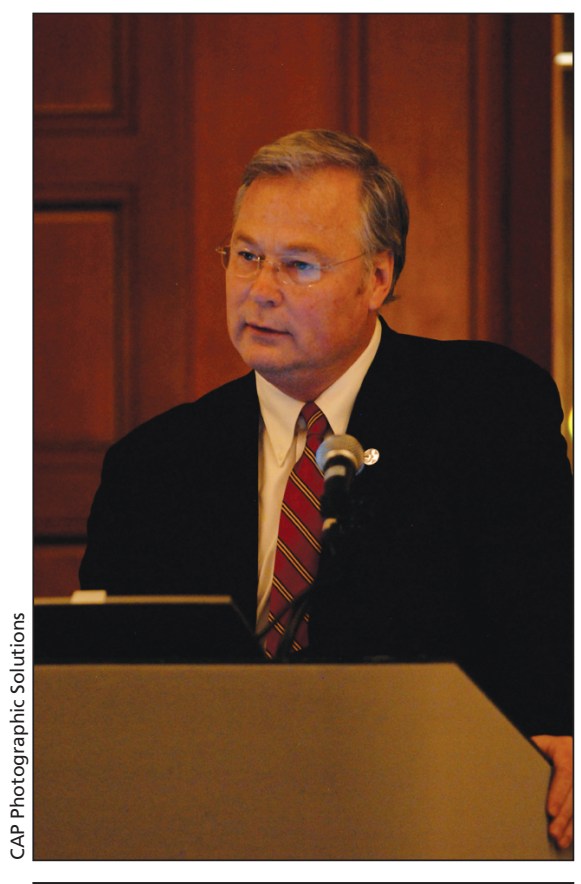

The health care system would be improved by the development of objective performance measures, says Dr. Jack Kitts, president and chief executive officer of the Ottawa Hospital in Ontario.

doctors in a room and asked them how best to measure the performance of, say, an emergency room, you would likely get many different answers.

"There is a lot of subjectivity in diagnoses and treatment," says Kitts. "If medicine were a pure science, we wouldn't need to have this argument."

Still, there is a need to get medical experts together and reach a consensus on which metrics work best, says Kitts. It is not acceptable for hospitals to make blanket statements about providing high-quality care without backing it up with proof, he says, but this often happens because there is no established gold standard for health care quality.

Even if experts did agree on which quality indicators should be measured, getting good data is no easy task. In the 1990s, Kitts says, several Ontario gallbladder surgeons lost their practices after a media investigation found that complication rates at their hospital were unusually high. But the problem wasn't with the surgeons, Kitts says, but with the way data about surgery complications was coded.

"Bad data can do harm," says Kitts. "It would be a crime to get rid of a hospital CEO or chief-of-staff because of bad data."

Good data alone is still not enough, several presenters at the CEO forum noted - transparency is vital to improving quality in health care, and hospitals should publicly release their performance data and be held accountable for underperforming. This might also create an environment of healthy competition among hospitals.

"I'm all for incentives," Kitts said in response to a question from the audience during a panel discussion. "The biggest incentive in health care is to see someone else doing better than you."

Though it might be difficult to get all health care institutions to release performance data, especially poor performers, such transparency is not unheard of. Maura Davies, president and chief executive officer of the Saskatoon Health Region, noted in her presentation that 29 long-term care facilities in her region agreed to follow a balanced scorecard. Each facility posts its data on a website (www.ltcquality.ca).

"All of them can access each other's data. That is quite astonishing," Davies told the audience.

Widespread support for adopting better health care quality measurements and promoting data transparency, however, may be a ways off.

"I'm optimistic that there will be a day when we will have objective performance measures that will allow us to improve the health care system," says Kitts. "How far in the future that is, I don't know. - Roger Collier, CMAJ

DOI:10.1503/cmaj.109-3191 